Veridiana Maria Brianezi Dignani de MOURA ${ }^{1}$ Giovana Wingeter di SANTIS $^{2}$

Renée laufer AMORIM² Júlio César BALIEIRO ${ }^{3}$

Enio Pedone BANDARRA ${ }^{2,3}$

Correspondência para:

VERIDIANAMARIA BRIANEZI DIGNANI DEMOURA

Setor de Patologia Animal

Departamento de Medicina Veterinária

Escola Veterinária

Universidade Federal de Goiás

Campus 2

Caixa Postal 131

74001-970 - Goiania-GO

vdmoura@vet.ufg.br

Recebido para publicação: 20/02/2004 Aprovado para publicação: 01/06/2005

\title{
Mensuração de hormônios andrógenos, estrógeno, fosfatase ácida prostática (PAP) e antígeno prostático específico (PSA) em cães adultos com próstata normal e hiperplásica
}

\author{
1 - Setor de Patologia Animal do Departamento de Medicina Veterinária da \\ Escola Veterinária da Universidade Federal de Goiás, Goiania - GO \\ 2 - Serviço de Patologia do Departamento de Clínica Veterinária da \\ Faculdade de Medicina Veterinária e Zootecnia da Universidade Estadual \\ Paulista, Botucatu - SP \\ 3 - Fundação de Ensino "Octávio Bastos" do Centro Universitário da \\ Fundação de Ensino Octávio Bastos, São João da Boa Vista - SP
}

\section{Resumo}

As doenças prostáticas constituem um problema comum em cães adultos e idosos. Uma das afecções mais freqüentes é a hiperplasia prostática benigna (HPB) que, tanto no cão como no homem, está associada ao avanço da idade e ao desequilíbrio hormonal. No presente trabalho foram mensurados hormônios andrógenos, estrógeno, fosfatase ácida prostática (PAP) e antígeno prostático específico (PSA) de 37 cães com idade superior a três anos, em função do aspecto microscópico da próstata. Encontraram-se baixos níveis de estrógeno e altas concentrações de PSA nos animais com algum tipo de hiperplasia. Os valores de PAP sérico e urinário também foram maiores nos cães com hiperplasia.

\section{Introdução}

A HPB é um aumento espontâneo da próstata induzido por hormônios, freqüente em cães adultos e idosos, sendo considerada a alteração mais comum da próstata canina, visto que cerca de $100 \%$ dos cães adultos inteiros desenvolvem evidências histológicas de hiperplasia com o avançar da idade ${ }^{2,22,31,41}$. Em relação aos fatores hormonais envolvidos na patogenia desta afecção, sabe-se que a testosterona, produzida nos testículos, é o principal andrógeno circulante do organismo, e dá origem a outros dois hormônios: a diidrotestosterona (DHT) e o $17 \beta$ estradiol, sendo todos abarcados no estabelecimento do processo $^{28}$.

A DHT é um mediador do crescimento prostático, está localizada principalmente nas células estromais da glândula e pode atuar de forma autócrina ou parácrina nas células epiteliais glandulares. Em ambos os tipos celulares, a DHT liga-se a receptores androgênicos nucleares que sinalizam a transcrição de fatores de crescimento mitogênicos para as células epiteliais e estromais. A testosterona pode ligar-se diretamente a estes receptores e estimular o crescimento celular, entretanto, a DHT é dez vezes mais potente por dissociarse mais lentamente dos receptores nucleares ${ }^{11,23,28}$.

O estrógeno $\left(\mathrm{E}_{2}\right)$, além de contribuir para o desenvolvimento da $\mathrm{HPB}$, sensibilizando a próstata para andrógenos ${ }^{19,38,43}$, leva ao aumento da formação de DHT na próstata, estimula o crescimento de musculatura lisa, a síntese de colágeno estromal e a metaplasia escamosa do epitélio ${ }^{4,13,14,28,36,43}$. De acordo com Coffey ${ }^{9}$ o estrógeno ainda diminui a taxa de apoptose, induz a inflamação, bloqueia a função secretora epitelial e adiciona adutos ao DNA das células prostáticas. 
O desequilíbrio nos níveis de andrógenos prostáticos altera a interação entre epitélio e estroma, visto que as células epiteliais respondem a estímulos de fatores de crescimento produzidos pelas estromais. Esta alteração pode resultar em um descontrole na proliferação, migração e morte celular, tornando-se um dos fatores que contribuem no desenvolvimento da $\mathrm{HPB}^{21,34}$

O primeiro marcador biológico utilizado no diagnóstico de afecções da próstata foi a fosfatase ácida, que se apresentava aumentada no soro de pacientes humanos com carcinoma prostático metastático. Corazza et al..$^{10}$ determinaram os valores séricos de PAP, fosfatase ácida não prostática (PAPN) e fosfatase ácida total (PAT) em cães controle e com doenças prostáticas. Em cães adultos saudáveis as concentrações séricas de PAT e PAP aumentavam com a idade. Da mesma forma, os níveis de PAP apresentavam-se aumentados em cães com HPB e, naqueles com câncer de próstata (CP), estes valores encontravam-se ainda mais elevados, firmando a dosagem da PAP um importante método diferencial entre as HPB e os CP.

Uma vez que o PSA foi escolhido como meio de detecção precoce do câncer de próstata em humanos ${ }^{5,27}$, surgiram dúvidas se esta enzima seria um bom marcador em outras espécies. Karr et al. ${ }^{25}$ utilizando análise por southern blot detectaram genes relacionados ao PSA humano em primatas, mas não em outros mamíferos, incluindo coelhos, bovinos, suínos, caninos, ratos e camundongos. Da mesma forma, Bell et al. ${ }^{6}$ avaliaram a concentração sérica e seminal de diferentes glicoproteínas prostáticas no cão, com o objetivo de testar o valor diagnóstico desses marcadores nas diversas afecções da glândula nesta espécie. Estes pesquisadores não detectaram PSA sérico ou seminal e a PAP não apresentou diferenças entre os animais normais e aqueles com HPB, prostatite e neoplasia.

Diante do exposto, o presente trabalho teve por objetivo verificar os valores séricos de
$\mathrm{E}_{2}, \mathrm{~T}_{4}$ e DHT, bem como as dosagens sérica e urinária de PSA ePAP em cães adultos, em função do diagnóstico histopatológico da próstata.

\section{Materiais e Métodos}

Foram utilizados 37 cães, com idade $=3$ anos, sem restrições quanto a raça. Os animais foram selecionados aleatoriamente, sem a necessidade de apresentarem histórico ou alterações clínicas relacionadas a algum tipo de afecção prostática. Mensuraram-se os valores séricos e urinários de fosfatase ácida prostática (PAP) e antígeno prostático específico (PSA), bem como os valores séricos de testosterona $\left(\mathrm{T}_{4}\right)$, diidrotestosterona (DHT) e estrógeno $\left(\mathrm{E}_{2}\right)$. Após a mensuração, estes valores foram avaliados considerando a classificação histopatológica da próstata.

\section{Amostras de soro e urina para as dosagens de PAP, PSA, $\mathrm{T}_{4}$, DHT e $\mathrm{E}_{2}$}

Amostras sangüíneas foram obtidas por punção da veia jugular, utilizando-se tubos Vacutainer (SST Gel and clot ativator, Becton Dickinson) e agulhas Vacutainer (21G1, Becton Dickinson ). Em seguida o sangue era centrifugado a $1500 \mathrm{rpm}$, durante cinco minutos, para obtenção do soro. As amostras de urina eram obtidas por sondas uretrais acopladas a seringas de $10 \mathrm{ml}$. Todas as amostras foram coletadas no período da manhã para diminuir variações nos valores hormonais decorrentes de oscilações circadianas normais ${ }^{15}$. O soro e a urina para a mensuração de todas as variáveis propostas (PAP, PSA, $\mathrm{T}_{4}$, DHT e $\mathrm{E}_{2}$ ) eram acondicionados em tubos de eppendorf, contendo $500 \mu \mathrm{l}$ de amostra, e congelados em freezer à $-20^{\circ} \mathrm{C}$, até o momento das dosagens $s^{10,18,38}$. As alíquotas de soro e urina destinadas as dosagens de PAP recebiam uma gota de ácido acético de acordo com indicação do fabricante, para que pudessem ser mantidas congeladas até o momento do processamento.

Dosagens séricas e urinárias de PAP e PSA As dosagens de PAP e PSA no soro e 
urina foram realizadas no Laboratório Clínico da Faculdade de Medicina da UNESP, Botucatu, SP, nos Serviços de Bioquímica e Sorologia, respectivamente. Para a mensuração da PAP, utilizou-se o equipamento de automação Technicon-RAXT, com kit comercial para dosagem de fosfatase ácida total e prostática (Biotrol Pac monoreactif, cód. A03034, Biotrol Diagnostic, França). As dosagens sérica e urinária do PSA foram efetuadas em equipamento automatizado Elecsys (Roche), por método de eletroquimioluminescência, utilizando kit comercial para a dosagem de PSA total (Elecsys total PSA immunoassay, cód. 1731262, Roche, Alemanha).

Testosterona, diidrotestosterona e estrógeno séricos As mensurações séricas de testosterona, diidrotestosterona e estrógeno foram realizadas no Laboratório de Dosagem Hormonal do Hospital Veterinário da Faculdade de Medicina Veterinária e Zootecnia, Universidade de São Paulo (USP), São Paulo, SP. Para as dosagens utilizaram-se os kits comerciais Testosterona total (CAR) - fase sólida (DPC Medlab); DHT (RIA ACTIVE) - fase sólida (DSL); e Estradiol $3^{a}$ geração (Ultra-sensível) - duplo anticorpo (DSL), para testosterona, diidrotestosterona e estrógeno, respectivamente. A técnica empregada para as mensurações foi a de radioimunoensaio, seguindo os protocolos convencionais e padronizados no Laboratório de Dosagem Hormonal da FMVZ - USP, São Paulo, SP.

\section{Resultados}

Foram mensuradas três variáveis hormonais séricas e verificada a diferença nestes valores considerando a classificação histopatológica das próstatas. Animais com próstata normal ou com hiperplasia não apresentaram diferenças significativas nos níveis de testosterona e diidrotestosterona. No entanto, os níveis séricos de estrógeno foram significativamente menores em glândulas com hiperplasia epitelial que nas normais, enquanto não diferiram daquelas acometidas pelos demais tipos de hiperplasia (Tabela 1). As médias de idade dos animais em função do diagnóstico histológico da próstata estão dispostas na Tabela 1.

Assim como as variáveis hormonais, também foram dosadas duas glicoproteínas séricas e urinárias (PSA e PAP), sendo que houve diferença estatística apenas nos valores de PSA sérico. Nesta variável observou-se que animais com próstata normal possuem níveis mais baixos que aqueles com hiperplasia epitelial (Tabela 2). As médias de PAP sérico e urinário dos diferentes grupos comparativos estão dispostas na Tabela 03 .

\section{Discussão}

Das variáveis hormonais séricas mensuradas neste estudo, apenas o estrógeno apresentou valores significativamente menores nos animais com hiperplasia epitelial em relação aos com próstata normal. Embora a diferença estatística tenha sido observada somente entre estes dois grupos, notou-se uma tendência a menores valores de estrógeno nos cães com algum tipo de hiperplasia. Brendler et al. ${ }^{7}$ utilizaram beagles para verificar as mesmas variáveis hormonais pesquisadas neste trabalho e não encontraram diferença nos níveis de estrógeno em animais de diferentes idades e com histologia variando de normal a hiperplásica, no entanto, em dois grupos os valores séricos deste hormônio também eram menores em animais com hiperplasia.

De outra parte, Klausner et al. ${ }^{28}$ afirmam que as concentrações de estrógeno permanecem constantes em caninos adultos inteiros. Já Souza e Toniollo ${ }^{38}$ sustentam que cães idosos apresentam nível sérico de estrógeno maior quando comparado ao de jovens e jovens adultos. Recentemente Kawakami et al. ${ }^{26}$ também obtiveram valores plasmáticos de estrógeno maiores em cães com hiperplasia prostática, especialmente naqueles com azospermia.

Um fato interessante observado no presente estudo é que além do estrógeno diminuir nos animais com próstata 
hiperplásica em relação aos de histologia normal, os valores deste hormônio oscilaram em função do tipo de hiperplasia, sendo menores nas epiteliais e maiores nas complexas. Com base nestes dados foi possível visualizar uma relação direta entre o diagnóstico histológico, a idade do animal e o nível sérico de estrógeno, constatandose que animais com hiperplasia epitelial eram adultos jovens (5,25 anos) e apresentaram os menores valores estrogênicos. Em contraste, cães com hiperplasia complexa eram mais velhos (6,33 anos) e demonstraram os maiores valores de estrógeno (Tabela 1). De forma similar Cochran et al. ${ }^{8}$ obtiveram um perfil estrogênico variado a depender da idade e do aspecto histológico da glândula. Apesar de não terem classificado o tipo de hiperplasia, cães jovens com próstata hiperplásica apresentaram menores valores em relação aos jovens normais e idosos com hiperplasia.

Os níveis séricos de testosterona e diidrotestosterona se mantiveram semelhantes nos quatro grupos estudados (Tabela 1), sendo que Juniewicz et al. ${ }^{24} \mathrm{e}$ Crone et al. ${ }^{12}$ obtiveram resultados similares quando compararam animais inteiros com hiperplasia e castrados normais e com hiperplasia. Vale ressaltar que os cães castrados dos estudos supracitados foram submetidos a reposição hormonal imediata ou tardia após a esterilização, por isso apresentaram algum tipo de hiperplasia e valores hormonais próximos aos dos animais inteiros.

Apesar de análogos, os valores de testosterona foram menores nos cães com hiperplasia em relação aos normais, exceto naqueles com hiperplasia epitelial, sendo que Kawakami et al. ${ }^{26}$ encontraram resultados semelhantes. O mesmo ocorreu com a diidrotestosterona, que tendeu a diminuir nos grupos com hiperplasia, afora naqueles com o tipo complexa. Seguindo o mesmo princípio, Barsanti e Finco ${ }^{3}$ e Klausner et al. ${ }^{28}$, descrevem o declínio das concentrações desses andrógenos com o decorrer da idade.
Lowseth et al. ${ }^{31}$ notaram um perfil inconstante para a variável testosterona em decorrência da idade e do diagnóstico histológico da próstata, sendo todos os cães acima de seis anos portadores de algum tipo de HPB. Estes pesquisadores apontaram o declínio da testosterona sérica em animais até nove anos e o restabelecimento desses níveis a partir dos doze. Tal aumento não foi observado nesta pesquisa, pois o animal mais velho apresentava onze anos de idade. Em contrapartida, Souza e Toniollo ${ }^{38}$ observaram uma tendência a maiores concentrações de testosterona em função da idade do animal, embora não tenha encontrado diferença significativa entre os grupos avaliados, nem determinado o perfil histológico da próstata desses cães.

Verificou-se que não há um padrão ou perfil hormonal sérico para animais de diferentes faixas etárias e com afecções prostáticas distintas. Ao contrário, foi possível constatar que o mais importante não são os valores maiores ou menores de um ou outro hormônio e sim o desequilíbrio na relação entre estes. Mais ainda, tal desproporção é fato concreto com o avançar da idade e primordial ao desenvolvimento das lesões prostáticas no cão, sobretudo da HPB. Dentre os artigos veterinários consultados, Brendler et al. ${ }^{7}$ são dos poucos que reportam o valor desta proporção hormonal alterada como ponto chave na evolução do tecido prostático. No que diz respeito aos humanos, Griffiths et al. ${ }^{19}$ também descrevem a importância da relação andrógeno/ estrógeno na gênese dos processos mórbidos da próstata.

Similar ao observado neste estudo, Souza e Toniollo ${ }^{38}$ encontraram ampla variação nas concentrações séricas hormonais dentro de cada grupo, indicada pelos altos desvios padrão. A mensuração hormonal é uma variável muitas vezes incontrolável, visto as normais oscilações em decorrência do ritmo circadiano ${ }^{15}$. Sabendo disso, as colheitas sangüíneas foram realizadas sempre no período da manhã em todos os animais para diminuir possíveis problemas com tais 
mensurações.

Apesar do zelo dispensado no controle das variáveis estudadas, não se pode relevar outros fatores que interferem na produção de tais hormônios, como idade, estresse e status geral de cada indivíduo. Talvez, devido a tudo isso raríssimos autores apresentem valores normais de referência para esses hormônios e a maioria trabalhe com base nos dados de cada estudo. Diante dos resultados foi possível constatar grande variabilidade nas concentrações séricas de estrógeno e andrógenos, especialmente em função do tipo de lesão do tecido prostático. No entanto, não é possível determinar um intervalo de variação padrão confiável em que se possa fundamentar ou suspeitar de uma lesão prostática benigna ou maligna.

Quanto as glicoproteínas mensuradas no plasma e na urina dos cães, apenas a variável PSA sérico foi significativamente menor em animais com próstata normal em relação aos com hiperplasia epitelial e, de modo geral, aos demais tipos de HPB. Embora os valores detectados estejam muito abaixo dos referenciais para o homem (até $4 \mathrm{ng} / \mathrm{ml}$ ), foi observado que, assim como em humanos, este marcador prostático pode aumentar em indivíduos portadores de hiperplasia ${ }^{20,29,33,35}$. Apesar de não diferir estatisticamente entre os grupos comparados, o PSA urinário também foi detectado e com tendência a aumentar em cães com hiperplasia prostática, conforme ilustra a Tabela 2.

Da mesma forma Laufer Amorim ${ }^{30}$ detectou a presença de PSA no soro e na urina de cães. Em contrapartida, Bell et al..$^{6}$ e Souza ${ }^{37}$ também visaram a dosagem desta variável na espécie canina e obtiveram resultados negativos, empregando a técnica de ensaio imunoenzimático de micropartículas (MEIA). Talvez, a metodologia e o kit utilizados justifiquem resultados opostos, visto que o método proposto nesta pesquisa e por Laufer Amorim $^{30}$ foi o da eletroquimioluminescência.

Karr et $a l .{ }^{25}$ não encontraram genes semelhantes ao PSA humano em caninos, contudo diversos autores reportam similaridades fisiológicas e bioquímicas entre esta glicoproteína humana e a esterase prostática secretória canina (CPSE), o maior produto de secreção da próstata canina ${ }^{16,17,23,32}$. Dada tais analogias bioquímicas e a alta sensibilidade do kit empregado neste estudo, questiona-se a possibilidade de reação cruzada e por isso a detecção de valores muito baixos no soro desses cães. Se realmente esta hipótese fosse válida, tratar-se-ia de uma reação falsopositiva, constituindo um novo motivo para mais uma vez descartar, como valor diagnóstico, a dosagem de PSA na espécie canina $^{40}$.

$\mathrm{Na}$ verdade, as tentativas de se dosar PSA nos cães partem do princípio das similitudes entre as afecções que ocorrem nas espécies canina e humana, mas diante dos resultados é razoável a constatação de que dessemelhanças existem e provavelmente conduzem a efeitos distintos em determinadas circunstâncias, como a alta e a baixa incidência das neoplasias prostáticas no homem e no cão, respectivamente. No entanto, os achados também suportam o PSA como um marcador útil para determinar a presença de lesão na próstata canina, mas não qualificar a mesma ${ }^{1,35}$. Ainda, mais estudos são necessários para determinar o valor normal máximo e o alterado mínimo na espécie canina.

No que diz respeito a PAP, não foi observada diferença entre os grupos comparativos, mas é nítido o aumento na concentração desta glicoproteína em função do tipo de hiperplasia, especialmente da forma complexa, conforme os dados apresentados na Tabela 3. Tais achados estão de acordo com Corazza et al. ${ }^{10}$ que encontraram valores séricos de PAP (total, prostático e não-prostático) particularmente elevados em cães com HPB e valores ainda maiores em animais com neoplasia prostática. Apesar de não ter se fundamentado no diagnóstico histológico, Laufer Amorim ${ }^{30}$ também detectou acréscimo nos valores séricos e urinários de PAP em função da idade. Vale ressaltar que 
93\% desses animais apresentavam algum tipo de lesão prostática, sendo mais freqüente as hiperplasias.

Em contraposição, Souza ${ }^{37}$ descreve o decréscimo da concentração sérica de PAP em função da idade. $\mathrm{O}$ fato de terem sido empregados kits comerciais humanos, mas diferentes, pode justificar resultados desiguais em ambos os trabalhos. Por outro lado, Klausner et al. ${ }^{28}$ e Bell et al. ${ }^{6}$ afirmam que não há diferença na dosagem de PAP quando comparados cães com próstata normal e com diferentes tipos de afecção.

Embora a utilização de marcadores prostáticos tenha revolucionado o diagnóstico das lesões prostáticas, especialmente a HPB e o câncer no homem, persiste a necessidade da avaliação minuciosa e heterogênea, empregando diferentes meios diagnósticos na determinação do tipo de lesão prostática em cada indivíduo. Quanto aos cães, é certo que a próstata canina secreta inúmeras proteínas, no entanto estas diferem daquelas produzidas na espécie humana em

Tabela 1-Médias dos valores séricos de estrógeno, testosterona, diidrotestosterona e idade em relação ao diagnóstico histopatológico ( $\mathrm{N}=37$ )

\begin{tabular}{|c|c|c|c|c|}
\hline \multirow[b]{2}{*}{ Grupo Comparativo } & \multicolumn{4}{|c|}{ Médias de Quadrado Mínimo } \\
\hline & $\mathrm{E}_{2}(\mathrm{pg} / \mathrm{ml})$ & $\mathrm{T}_{4}(\mathrm{ng} / \mathrm{ml})$ & $\mathrm{DHT}(\mathrm{pg} / \mathrm{ml})$ & Médias de Idade \\
\hline Normal $(\mathrm{n}=6)$ & $31,01^{\mathrm{a}}$ & $1,14^{\mathrm{a}}$ & $71,66^{a}$ & 3,5 \\
\hline Hiperplasia Epitelial $(n=4)$ & $4,73^{b}$ & $1,56^{\mathrm{a}}$ & $51,06^{a}$ & 5,25 \\
\hline Hiperplasia Complexa $(\mathbf{n}=15)$ & $17,65^{a b}$ & $1,04^{\mathrm{a}}$ & $91,36^{\mathrm{a}}$ & 6,33 \\
\hline Hiperplasia Estromal $(\mathrm{n}=12)$ & $8,93^{a b}$ & $0,92^{a}$ & $67,52^{a}$ & 6,91 \\
\hline
\end{tabular}

Médias seguidas pela mesma letra não diferem entre si pelo teste de Tukey $(p<0,05)$. Notar a variação na relação $E_{2} / T_{4}$ em função do tipo de hiperplasia

Tabela 2-Médias dos valores séricos e urinários de PSA em relação ao diagnóstico histopatológico ( $\mathrm{N}=37)$

\begin{tabular}{lcc}
\hline & \multicolumn{2}{c}{ Médias de Quadrado Mínimo } \\
Grupo Comparativo & PSA sérico(ng/ml) & PSA urinário $(\mathrm{ng} / \mathrm{ml})$ \\
\hline Normal $(\mathrm{n}=6)$ & $0,0021^{\mathrm{a}}$ & $0,0036^{\mathrm{a}}$ \\
Hiperplasia Epitelial $(\mathrm{n}=4)$ & $0,0082^{\mathrm{b}}$ & $0,0080^{\mathrm{a}}$ \\
Hiperplasia Complexa $(\mathrm{n}=15)$ & $0,0046^{\mathrm{ab}}$ & $0,0062^{\mathrm{a}}$ \\
Hiperplasia Estromal $(\mathrm{n}=12)$ & $0,0029^{\mathrm{ab}}$ & $0,0052^{\mathrm{a}}$ \\
\hline
\end{tabular}

Médias seguidas pela mesma letra não diferem entre si pelo teste de Tukey $(\mathrm{p}<0,05)$. Notar o aumento nas médias de PSA em função do tipo de hiperplasia

Tabela 3 - Médias dos valores séricos e urinários de PAP em relação ao diagnóstico histopatológico ( $\mathrm{N}=37)$

\begin{tabular}{ccc}
\hline & Médias de Quadrado Mínimo & \\
Grupo Comparativo & PAP sérico $(\mathrm{U} / \mathrm{l})$ & PAP urinário $(\mathrm{U} / \mathrm{l})$ \\
\hline Normal $(\mathrm{n}=6)$ & $0,91^{\mathrm{a}}$ & $1,70^{\mathrm{a}}$ \\
Hiperplasia Epitelial $(\mathrm{n}=4)$ & $1,17^{\mathrm{a}}$ & $1,12^{\mathrm{a}}$ \\
Hiperplasia Complexa $(\mathrm{n}=15)$ & $1,21^{\mathrm{a}}$ & $2,56^{\mathrm{a}}$ \\
Hiperplasia Estromal $(\mathrm{n}=12)$ & $1,09^{\mathrm{a}}$ & $2,03^{\mathrm{a}}$ \\
\hline
\end{tabular}

Médias seguidas pela mesma letra não diferem entre si pelo teste de Tukey $(\mathrm{p}<0,05)$. Notar o aumento nas médias de PAP em função do tipo de hiperplasia 
relação à quantidade, qualidade e atividade biológica, restringindo comparações exatas e limitando o uso desses marcadores no diagnóstico das afecções prostáticas caninas.

\section{Conclusões}

Os kits comerciais humanos utilizados para a dosagem sérica de $\mathrm{T}_{4}, \mathrm{DHT}, \mathrm{E}_{2}, \mathrm{PSA} \mathrm{e}$ PAP foram eficazes em detectar cada uma destas substâncias no soro de cães. A concentração sérica de estrógeno foi significativamente menor em cães com hiperplasia epitelial, sendo observados menores valores deste hormônio em todos os grupos com alguma forma de HPB. Os valores médios de $\mathrm{T}_{4}$ e DHT séricos oscilaram em função do diagnóstico histomorfológico da próstata. Houve diminuição na proporção sérica $\mathrm{E}_{2} / \mathrm{T}_{4}$ em função da presença de $\mathrm{HPB}$ e alteração variável na proporção $\mathrm{E}_{2} / \mathrm{T}_{4} / \mathrm{DHT}$ de acordo com a classificação histológica das glândulas. O nível de PSA sérico foi estatisticamente maior nos animais com hiperplasia epitelial e, de modo geral, em todos com os demais tipos de HPB. Ainda, as concentrações de PSA urinário e PAP sérico foram maiores nos grupos de cães com HPB, sendo todas estas variáveis representativas do perfil histológico da próstata canina.

\section{Agradecimento}

Apoio financeiro: Conselho Nacional de Desenvolvimento Científico e Tecnológico - CNPq.

\title{
Androgens, estrogen, prostatic acid phosphatase (PAP) and prostatic specific antigen (PSA) measure in adult male dogs with normal and hyperplasic prostate
}

\begin{abstract}
Prostatic diseases have been a common problem in middle age and older intact male dogs. Among these, benign prostatic hyperplasia (BHP) is the most frequent, age-related and hormonal-dependent condition of human and canine prostate. Blood samples were collected from 37 male intact dogs, tree years old dogs or more to determine androgens, estrogen, prostatic acid phosphatase (PAP) and prostatic specific antigen (PSA) according to histopathological aspects. Low levels of estrogen and high levels of prostatic specific antigen (PSA) were founded in dogs with BHP, respectively. Seric and urinary PAP levels were high in dogs with hyperplasia.
\end{abstract}

\section{Referências}

1 ARMBRUSTER, D. A. Prostatic-specific antigen: biochemistry, analytical methods and clinical application. Clin. Chem., v. 39, n. 2, p. 181-195, 1993.

2 BARSANTI, J.A. Prostatic hyperplasia: medical therapy. Proc. Am. Clin. Vet. Int. Med., v.17, p.536538, 1999.

3 BARSANTI, J.A., FINCO, D.R. Moléstias prostáticas do cão. In: ETTINGER, S.J. (Eds). Tratado de medicina interna veterinária. 3.ed. São Paulo: Manole, v.4, 1992, p.1941-1963.

4 BARTSCH, G.; KEEN, F.; DAXENBICHLER, G.; MARTH, C.H.; MARGREITER, A.; BRÜNGGER, A.; SUTTER, T.; ROHR, H.P. Correlation of biochemical (receptors, endogenous, tissue hormones) and quantitative morphologic (stereologic) findings in normal and hyperplastic human prostates. J. Urol., v.137, p.559-564, 1987.

5 BEDUSCHI, R.; OESTERLING, J.E. Prostate-Specific antigen. In: KNOBIL, E., NEILL, J.D. Encyclopedia of reproduction. San Diego: Academic Press, 1999, v. 4, p. 86-95.

6 BELL, F.W.; KLAUSNER, J.S.; HAYDEN, D.W.; LUND, E.M.; LIEBENSTEIN, B.B.; FEENEY, D.A.; JOHNSTON, S.D.; SHIVERS, J.L.; EWING, C.M.; ISAACS, W.B. Evaluation of serum and seminal plasma markers in the diagnosis of canine prostatic disorders. J. Vet. Intern. Med., v. 9, n. 3, p.149-153, 1995.

7 BRENDLER, C.B.; BERRY, S.J.; EWING, L.L.; MCCULLOUGH, A.R.; COCHRAN, R.C.; 
STRANDBERG, J.D.; ZIRKING, B.R.; COFFEY, D.S.; WHEATON, L.G.; HILER, M.L.; BORDY, M.J.; NISWENDER, G.D.; SCOTT, W.W. Spontaneous benign prostatic hyperplasia in the beagle: Age associated changes in serum hormone levels, and the morphology and secretory function of the canine prostate. J. Clin. Invest., v. 71, p. 1114-1123, 1983.

8 COCHRAN, R.C.; EWING, L.L.; NISWENDER, G.D. Serum levels of follicle stimulating hormone, luteinizing hormone, prolactin, testosterone, 5? dihydrotestosterone, 5? androstane 3 ?, 17 ? diol, 5? androstane 3 ?, 17 ? diol, and 17 ? estradiol from male beagles with spontaneous or induced benign prostatic hyperplasia. Investigative Urology, v. 19, n. 3, p. 142147, 1981.

9 COFFEY, D.S. Similarities of prostate and breast cancer: evolution, diet, and estrogens. Urology, v. 57, s.4a, p. 31-38, 2001

10 CORAZZA, M.; GUIDI, G.; ROMAGNOLI, S.; TOGNETTI, R.; BUONACCORSI, A. Serum total prostatic and non-prostatic acid phosphatase in healthy dogs and in dogs with prostatic diseases. J. Small Anim. Pract., v. 35, p. 307-310, 1994.

11 COTRAN, R. S.; KUMAR, V.; ROBBINS, S.L. The male genital tract. In:_ Robbins, Pathological basis of disease. 6ed. Philadelphia: W.B. Saunders, 1999, p.1011-1034.

12 CRONE, J.K.; BURNETT, A.L.; CHAMNESS, S.L.; STRANDBERG, J.D.; CHANG, T.S.K. Neuronal nitric oxide synthase in the canine prostate: aging, sex steroid, and pathology correlations. Journal of andrology, $v$. 19, n. 3, p. 358-364, 1998.

13 EPSTEIN, J.I. Non-neoplastic diseases of the prostate. In: BOSTWICK, D.E., EBLE, J.N. Urologic Surgical Pathology, St Louis: Mosby. 1997. p.307-16.

14 EWING, L.L.; BERRY, S.J.; HIGGINBOTTOM, E.G. Dihydrotestosterone concentration of beagle prostatic tissue: effect of age and hyperplasia. Endocrinology, v.113, n. 6, p.2004-2009, 1983.

15 FELDMAN, E.C.; NELSON, R.W. In: Feldman, Canine and feline endocrinology and reproduction. 2ed. Philadelphia: W.B. Saunders, 1996, p. 673-690.

16 FRENETTE, G.; DUBÉ, J.Y.; LACOSTE, D. TREMBLAY, R.R. Radioimmunoassay in blood plasma of arginine esterase: the major secretory product of dog prostate. The Prostate, v.10, p. 145-152, 1987.

17 GOBELLO, C.; CASTEX, G.; CORRADA, Y. Serum seminal markers in the diagnosis of disorders of the genital tract of the dog: a mini-review. Theriogenology, v. 57, p. 1285-1291, 2002.

18 GRAVES, H.C.B.; WEHNER, N.; STAMEY, T.A. Comparison of a polyclonal and monoclonal immunoassay for PSA: need for an international antigen standard. J. Urol., v. 144, p. 1516-1522, 1990.
19 GRIFFITHS, K.; EATON, C.L.; HARPER, M.E.; PEELING, B.; DAVIES, P. Steroid hormones and the pathogenesis of benign prostatic hyperplasia. Eur. Urol., v.20, s. 2, p.68-77, 1991.

20 HASUI, Y.; MARUTSUKA, K.; ASADA, Y.; IDE, H.; NISHI, S.; OSADA, Y. Relationship between serum prostate specific antigen and histological prostatitis in patients with benign prostatic hyperplasia. The Prostate, v. 25 , p. 91-96, 1994.

21 JANULIS, L.; LEE, C. Prostate gland. In: KNOBIL, E., NEILL, J.D. Encyclopedia of reproduction. San Diego: Academic Press, 1999, v. 4, p.77-85.

22 JOHNSTON, S.D.; KAMOLPATANA, K.; ROOTKUSTRITZ, M.V.; JOHNSTON, G.R. Prostatic disorders in the dog. Animal Reprodduction Science, v.60, n. 61, p.405-415, 2000

23 JOHNSTON, S.D., ROOT-KUSTRITZ, M.V., OLSON, P.M.S. In: Canine and Feline Theriogenology. Philadelphia: WB Saunders, 2001, 592p.

24 JUNIEWICZ, P.E.; BERRY, S.J.; COFFEY, D.S.; STRANDBERG, J.D.; EWING, L.L. The requirement of the testis in establishing the sensitivity of the canine prostate to develop benign prostatic hyperplasia. J. Urol., v.152, p.996-1001, 1994.

25 KARR, J.F.; KANTOR, J.A.; HAND, P.H. EGGENSPERGER, D.L.; SCHOLM, J. The presence of prostatic-specific antigen related genes in primates and the expression of recombinant human prostate-specific antigen in a transfected murine cell line. Cancer Res., v. 55, p. 2455-2462, 1995

26 KAWAKAMI, E.; AMEMIYA, E.; KASHIWAGI, C.; HORI, T.; TSUTSUI, T. High plasma estradiol-17? levels in dogs with benign prostatic hyperplasia and azoospermia. J. Vet. Med. Sci., v. 63, n. 4, p. 407-412, 2001.

27 HAN, M.A.; PARTIN, A.W.; RITTENHOUSE, H.G.; MIKOLAJCZYK, S.D.; SOKOLL, L.J.; CHAN, D.W.; VELTRI, R.W. Evaluation of prostate specific antigen for early detection of prostate cancer in men with a total prostate specific antigen range of 4.0 to $10.0 \mathrm{ng} / \mathrm{ml}$. J. Urol., v. 170, p. 723-726, 2003.

28 KLAUSNER, J.S.; BELL, F.W.; HAYDEN, D.W.; JOHNSTON, S.D.; LUND, E.M. Recent developments in the diagnosis and treatment of $\mathrm{BPH}$ and prostatic carcinoma. Proc. Am. Coll. Vet. Int. Med., p.547-548, 1994.

29 KOZLOWSKI, J.M. Prostate Cancer. In: KNOBIL, E., NEILL, J.D. Encyclopedia of reproduction. San Diego: Academic Press, 1999, v. 4, p. 67-76.

30 LAUFER AMORIM, R. Estudo clínico, laboratorial e anatomopatológico das próstatas de cães adultos. Botucatu, 2001. 116p. Tese (Doutorado) - Faculdade de Medicina Veterinária e Zootecnia, Universidade Estadual Paulista (UNESP). 
31 LOWSETH, L.A.; GERLACH, R.F.; GILLETT, N.A.; MUGGENBURG, B.A. Age-related in the prostate and testes of the beagle dog. Vet. Pathol., v.37, p.347-53, 1990.

32 McENTEE, M.; ISAACS, W.; SMITH, C. Adenocarcinoma of the canine prostate: immunohistochemical examination for secretory antigens. The Prostate, v. 11, p. 163-170, 1987.

33 MONTINORI, R.; MAZZUCCHELLI, R.; ALGABA, F.; BOSTWICK, D.G.; KRONGRAD, A. Prostate specific antigen as a marker of prostate disease. Virchows Arch., v. 436, p. 297-304, 2000.

34 NIU, Y.; MA, T.X.; ZHANG, J.; XU, Y.; HAN, R.F.; SUN, G. Androgen and prostatic stroma. Asian J. Androl., v. 1, p. 19-26, 2003.

35 OESTERLING, J.E. Prostate specific antigen: a critical assessment of the most useful tumor marker for adenocarcinoma of the prostate. J. Urol., v. 145, p. 907-923, 1991

36 POULET, F. Evolution de la prostate canine en fonction de l'âge. Ann. Med. Vet., v.129, p.567-584, 1985.

37 SOUZA, F.F de Estudo da próstata canina pelo exame ultra-sonográfico, palpação retal, dosagens séricas de testosterona, 17?-estradiol, fosfatase ácida prostática e antígeno específico prostático. Jaboticabal, 1998. 85p. Dissertação (mestrado). Faculdade de Ciências Agrárias e Veterinárias, Universidade Estadual Paulista (UNESP).

38 SOUZA, F.F.; TONIOLLO, G.H. Avaliação da glândula prostática canina. Rev. Bras. Reprod. Anim., v. 23, n. 3, p. 243-245, 1999

39 SOUZA, F.F., TONIOLLO, G.H. Marcadores de tecido prostático no cão. Revista CRMV-SP, v. 4, n. 3, p.63-70, 2001.

40 SWINNEY, G.R. Prostatic neoplasia in five dogs. Aust. Vet. J., v. 76, n. 10, p. 669-674, 1998. 